\title{
DocUmentos
}

\section{Panamá: el istmo de la discordia. Documentos relativos a la separación de Panamá y a la normalización de las relaciones entre Estados Unidos y Colombia.}

\section{Patricia Cardona Zuluaga ${ }^{1}$ Universidad EAFIT (Colombia)}

\section{La Guerra de los Mil Días y la separación de Panamá}

El fin del siglo XIX y el inicio del siglo XX en Colombia estuvo marcado por hechos luctuosos que dejaron una huella profunda en su historia. Desde 1885 el país había transformado su faz política gracias al ascenso del llamado proyecto regeneracionista, cuyos más notables líderes, entre ellos Rafael Núñez (1825-1894), Miguel Antonio Caro (1843-1909) y José Manuel Marroquín (1827-1908), abogaban por el retorno del centralismo y la promulgación de una serie de principios de identidad sustentados en la religión católica, la defensa del español y una férrea convicción acerca de la grandiosa herencia dejada por la colonización española en tierras americanas.

La Regeneración fue la respuesta conservadora al proyecto federativo encabezado por los liberales radicales colombianos a partir de 1850, cuyos propósitos se vieron encarnados en la Constitución de 1863, que además de promulgar un Estado Federal (Estados Unidos de Colombia), conformado por nueve Estados Soberanos, propició el afianzamiento del liberalismo en el país, expresado en la libertad de cultos, de conciencia, de prensa y en la formalización de un Estado secular que estableció un sistema educativo universal, laico y obligatorio con el objetivo de conducir a la sociedad por la senda civilizadora.

\footnotetext{
${ }^{1}$ (azuluaga@eafit.edu.co) Historiadora, Magíster en Historia, Doctora en Historia (Universidad de los Andes, Bogotá-Colombia). Profesora asociada del Departamento de Humanidades de la Universidad Eafit (Medellín-Colombia). Miembro del grupo de Investigación Estudios sobre Filosofía, Hermenéutica y Narrativas de la misma universidad. Este texto se deriva de la Investigación sobre las relaciones entre escritura histórica y retórica en el siglo XIX colombiano que en la actualidad adelanta con el apoyo de la Universidad EAFIT.
} 
La Regeneración cobró forma a partir de 1886, año en que se proclamó la Constitución que rigió los destinos de Colombia hasta 1991. Uno de los aspectos más relevantes de aquella carta magna, además de su afán centralista y el fortalecimiento del poder ejecutivo con sede en Bogotá, fue el debilitamiento de los Estados Soberanos, a través de una reforma administrativa que los degradó a Departamentos, es decir, pasaron a ser entidades político-administrativas dependientes del poder ejecutivo. Asimismo, los gobiernos regeneracionistas cerraron, de manera sucesiva, el acceso de los liberales a las burocracias administrativas en todos los niveles (nacional, departamental y local) lo que llevó a éste grupo político a declarar la guerra y a sostener la lucha mediante guerrillas mal preparadas, que fueron, casi siempre reprimidas por el ejército Conservador, mejor organizado y entrenado.

La Guerra de los Mil Días no es el objeto de esta presentación, por lo tanto no nos remitiremos a detalles, puesto que en el marco del documento que vamos a presentar interesa este acontecimiento por que fue el desencadenante de eventos que tuvieron repercusión internacional. La Guerra de los Mil Días fue un hecho deplorable para Colombia: los más de cien mil muertos que dejaron los combates, en un país que contaba en la época con aproximadamente cinco millones de habitantes, enfatizaron el sentimiento de desazón por la degradación que alcanzó la pugna. Pero el hecho que profundizó la herida abierta dejada por la conflagración, fue la desmembración de Panamá el 3 de noviembre de 1903, un año después de que se firmara el Tratado de Wisconsin, que negociaba el fin de la guerra (21 de Noviembre de 1902), y seis meses luego de que el Gobierno declarara oficialmente el cese de las hostilidades (11 de Junio de 1903).

\section{Los frágiles lazos de la unidad colombiana}

Después de su independencia de España, Panamá se anexó a la entonces llamada por los historiadores Gran Colombia en 1821; una vez disuelto aquel vasto experimento de unidad latinoamericana con la desmembración Ecuador y Venezuela, Panamá siguió unida al destino de Colombia. Pero la unión nunca fue estable y el istmo, como entonces se le llamaba, jamás se unió de manera cabal a Colombia, prueba de ellos fueron los intentos de separación y breves secesiones a lo largo del siglo XIX: en 1830, 1831, 1840 y 1861, año en el que cobra vida la Confederación Granadina conformada por nueve Estados Soberanos, entre ellos el de Panamá.

El lazo entre Panamá y Colombia fue siempre frágil; conscientes de esa situación, las autoridades colombianas intentaron crear los mecanismos jurídicos que garantizaran su permanencia en la República. Uno de esos intentos 
fue la firma en 1846 del Tratado Mallarino-Bidlack, que creaba las condiciones para la construcción de un ferrocarril que uniría el Océano Atlántico con el Pacífico, permitía el libre tránsito de los ciudadanos norteamericanos por el istmo, así como la defensa de la soberanía colombiana en ese territorio. Una vez construido el ferrocarril de Panamá (1850-1855) se confirmó la importancia estratégica de Panamá para las grandes potencias de la época, especialmente Estados Unidos e Inglaterra, y se hizo mucho más viable la construcción de un canal que comunicara el Atlántico con el Pacífico, proyecto indispensable para el afianzamiento geoestratégico de las potencias señaladas.

A partir de 1850, la tensión por el control del istmo, así como los planes consecutivos por construir un canal en Centroamérica, fueron un punto sustantivo en las relaciones internacionales de Colombia, fundamentalmente con los Estados Unidos. Inglaterra ya había explorado la viabilidad de construir un paso a la altura de Nicaragua y de Costa Rica para mantener su poderío en la región y asegurar el dominio sobre Estados Unidos². La construcción de un canal interoceánico aseguraba a las potencias un lugar protagónico en el mundo, a los colombianos se les presentaba como la oportunidad para mejorar las finanzas y a los panameños como la única posibilidad de salir de la postración económica y social en la que se hallaban³.

Así pues, el control de Panamá no sólo era un problema de política interna del Estado colombiano; era, sobre todo, la confluencia de las tensiones de dominio entre una potencia en declive como Inglaterra, y otra emergente como Estados Unidos, que reclamaba para sí una especie de derecho de dominio sobre todo el continente americano. A fin de suavizar las relaciones entre las potencias, así como asegurar el equilibrio de poderes en la región, norteamericanos e ingleses firmaron en 1850 el Tratado Clayton-Bulwer, en el que pactaban no controlar en exclusiva el canal que cualquiera de ellos construyese en la región, ya fuera en Nicaragua, Costa Rica o Panamá4.

En síntesis, pese a la importancia internacional de Panamá, la región estaba postrada por las guerras civiles que desangraban a Colombia, aunque éstas no tuvieran su centro de operaciones en el istmo. Para los panameños la casi

\footnotetext{
${ }^{2}$ Sobre las alternativas que se estudiaron para la construcción de un canal interoceánico veáse: Araúz, Celestino Andrés, "Un sueño de siglos: el Canal de Panamá". En http://bibliotecavirtual. clacso.org.ar/ar/libros/panama/cela/tareas/tar123/02arauz.pdf, Ingreso: febrero 03 de 2015

3 Uno de los libros más importantes que se han escrito sobre las viscitudes de la negociación y construcción del canal de Panamá es: McCullough, David, The path between the seas. The creation of the Panama Canal, 1870-1914, New York, Simon Schuster, 1977. Puede consultarse en español como; McCullough, David, Un camino entre dos mares: la creación del Canal de Panamá, Madrid, Espasa Calpe, 2004. Sobre la historia de las relaciones entre Panamá y Colombia véase: Bonilla Heraclio, Montañez Gustavo (Editores), Colombia y Panamá la metamorfosis de la nación en siglo $X X$, Bogotá Universidad Nacional de Colombia, Red de Estudios de Espacio y Territorio RET, Departamento de Historia de la Universidad Nacional, Convenio Andrés Bello, 2004.

4 Puede consultarse en: http://www.oas.org/columbus/docs/Tratado\%20Clayton-Bulwer\%20 $\% 281850 \% 29$.pdf Ingreso: febrero 05 de 2015.
} 
única posibilidad que tenían de mejorar sus condiciones estaba subordinada a la construcción del canal, que era, a finales del siglo XIX, un proyecto colosal que Colombia no estaba en condiciones de hacer, dado que requería grandes dosis de capital extranjero.

En 1880 los franceses, encabezados de Ferdinand de Lesseps (1805-1894), iniciaron la construcción de un canal que excavaría las 20 leguas que separaban los océanos Atlántico y Pacífico en el punto del istmo ${ }^{5}$, pero las negociaciones habían empezado en 1878 con Lucien Napoleón Bonaparte Wyse (1845-1909), quien finalmente obtuvo la concesión del Gobierno de los Estados Unidos de Colombia para la perforación del canal. Ferdinand de Lesseps seguro de que su experiencia como constructor del Canal de Suez era una carta segura para el éxito de la empresa canalera y para la obtención de los empréstitos necesarios para su ejecución, compró a Bonaparte Wyse la concesión ${ }^{6}$. Lesseps ignoró las condiciones geográficas en las que habría de llevarse a cabo la obra, esto es, la humedad del terreno, las lluvias torrenciales que paraban las actividades y las enfermedades tropicales que mataban a trabajadores e ingenieros. Así pues, cinco años después de iniciados los trabajos, la empresa de Lesseps agobiada por las deudas debió parar las obras y, finalmente, en 1889 se declaró en quiebra.

\section{La intervención norteamericana en pos del canal}

El canal quedó en vilo hasta finales de la década de 1898, cuando la lucha de los cubanos por emanciparse de España mostró a los Estados Unidos la necesidad de tener un paso que agilizara el tránsito y permitiera la reunión rápida de sus flotas. La construcción del canal se convirtió en un problema de seguridad nacional para los Estados Unidos. Entonces resurgió la discusión sobre el punto idóneo para las excavaciones y sobre la cuestión diplomática de la soberanía de los países implicados (Nicaragua, Costa Rica y Colombia).

La ley Spooner firmada por el Congreso de los Estados Unidos en Junio de 1902 autorizaba al gobierno norteamericano a comprar la mayor parte de las acciones de la quebrada empresa de Lesseps y los activos del ferrocarril de Panamá y a negociar con Colombia la continuación de las obras de excavación

\footnotetext{
5 En la Biblioteca Nacional de Colombia pueden consultarse documentación relativa a la construcción del canal interoceánico, véase: Fondo Quijano 16, pieza 8. Proyecto de Lei. Concediendo privilejio exclusivo para la construcción de un canal interocé́nico entre el Golfo de San Miguel i la Ensenada de Caledonia o Puerto Escocés, Bogotá, Imprenta de Echavarría Hermanos, 1852. Fondo Pineda 825. Canal Interocénico: proyecto propuesto al congreso nacional de los Estados Unidos de Colombia por Daniel W. Teller, de Nueva York, ciudadano Norteamericano, para la celebración de un contrato de privilejio para la excavación de un canal interoceánico por el istmo de Panamá, entre los paralelos $8^{\circ} i 10^{\circ}$ latitud norte. Bogotá, Imprenta de Echavarría Hermanos, 1866. También. Fondo Pineda 942, pieza 14. Documentos relativos al canal interoceánico. Bogotá, Imprenta i estereotipia de Medardo Rivas, 1870

${ }^{6}$ Roman, Eduardo, Panamá y su separación de Colombia, Bogotá, Editorial Pluma, 1972, 2ª Ed.
} 
en el istmo. De no ser posible el último punto, los diplomáticos norteamericanos estaban facultados para acordar con Costa Rica o Nicaragua la construcción del canal en sus territorios. El paso interoceánico era para los norteamericanos un proyecto inaplazable e incuestionable.

La ley Spooner fue el punto de partida para la negociación del Tratado Herrán-Hay que debatieron durante dos años Colombia y Estados Unidos, (1902 y 1903) para establecer los lineamientos de la construcción del canal y los asuntos relativos a la soberanía de Colombia en la zona ${ }^{7}$.

Pero previo a este Tratado, y alertados probablemente por los efectos de la guerra en Panamá y sus consecuencias sobre el funcionamiento del Ferrocarril de Panamá, Estados Unidos e Inglaterra firmaron el 18 de Noviembre de 1901 un acuerdo bilateral, que ignoró a Colombia, el Tratado Hay-Pauncefote que derogaba el Tratado Clayton-Bulwer y declaraba la zona del canal como de interés internacional. Con este tratado los ingleses reconocían a la vez su pérdida de influencia en la zona y la hegemonía de los Estados Unidos en ella, además liberaban diplomáticamente a Estados Unidos para construir el canal. Al ser declarada la zona como de interés internacional, los colombianos perdieron las facultades referidas a los permisos de construcción, y a la intervención militar en la zona, por lo que solamente les quedaba negociar aspectos asociados a la soberanía en las franjas aledañas a la excavación así como al uso y usufructo del canal ${ }^{8}$. Estados Unidos asumió el derecho a intervenir militarmente en la región en caso de guerra en Colombia para asegurar la normalidad de las operaciones del Ferrocarril y del futuro canal, de modo que en plena Guerra de los Mil Días, los Estados Unidos, facultados por el Hay Pauncefote mandaron tropas a resguardar el área en la que se concentrarían los trabajos.

Esta fue la situación que precedió el Tratado Herrán-Hay entre Colombia y Estados Unidos. En este contexto, el Estado colombiano no tenía mayor capacidad de negociación, y los esfuerzos se encaminaron a impedir que Colombia perdiera totalmente el control del futuro canal. Problemas como la soberanía colombiana, la intervención de las tropas norteamericanas, o el tránsito por las zonas comprometidas en las excavaciones no podían entrar en las discusiones diplomáticas; estos asuntos habían sido pactados entre Inglaterra y Estados Unidos en el Tratado Hay-Pauncefote. Un punto crucial

\footnotetext{
${ }^{7}$ Una versión electrónica del Tratado Herrán-Hay puede consultarse en: http://www-rohan.sdsu. edu/dept/polsciwb/brianl/docs/1903HayHerranTreaty.pdf Ingreso, febrero 4 de 2015. Sobre el mismo tratado pueden consultarse algunos estudios clásicos: Uribe Uribe, Antonio José, Las modificaciones al Tratado entre Colombia y los Estados Unidos, Bogotá, Imprenta Nacional, 1921. Castillero, J. Ernesto, La causa inmediata de la emancipación de Panamá: historia de los origenes, la formación y el rechazo del Senado Colombiano al Tratado Herrán Hay, Panamá, Imprenta Nacional, 1933. Miner, Dwight Carroll, The fight for the Panama route: The story of the Spooner Act an the Hay Herran treaty, New York, Columbia University Press, 1940.

${ }^{8}$ El Tratado Hay Pauncefote puede consultarse en: http://www.enriquebolanos.org/tratados pdf/68_TRATADO_hay-pauncefote.pdf Ingreso: febrero 04 de 2015
} 
en las discusiones del Tratado Herrán-Hay fue el de la indemnización de 10 millones de dólares y 250 mil dólares anuales (hasta 1917) a cambio de los activos de la empresa de Lesseps y la pérdida de control colombiano sobre la zonas comprometidas en las excavaciones.

\section{La desmembración de Panamá y el rencor de Colombia}

En este estado de cosas, el Senado colombiano se opuso a la ratificación del Tratado Herrán-Hay por considerar que lesionaba la soberanía nacional al permitir a los Estados Unidos la posesión de derechos y privilegios por cien años, prorrogables en la franja que comprendía 5 kilómetros a lado del canal; consideraban además que la indemnización era irrisoria toda vez que se esperaban mayores réditos de posteriores negociaciones. Por otra parte, la recién terminada Guerra de los Mil Días había dejado resentimientos tan profundos entre las bancadas políticas que oponerse al Tratado significaba para muchos debilitar al gobierno de turno y menguar el poderío político de los conservadores.

El Tratado fue rechazado el 12 agosto de 1903, lo que unió a la élite panameña alrededor de los cuestionamientos sobre legitimidad del gobierno colombiano en el istmo, al tiempo que pregonaban el derecho a autogobernarse como república independiente de Colombia. A partir de entonces se desataron los eventos que dieron vía libre a la separación del Departamento de Panamá el 3 de Noviembre de 1903 con el apoyo irrestricto de los Estados Unidos, quienes apenas tres días después y sin esperar siquiera que el gobierno colombiano con sede en Bogotá estuviera enterado de la secesión, reconoció a Panamá su existencia republicana y se comprometió a protegerle de las intenciones colombianas de represión militar del movimiento separatista. Desde el momento mismo de la secesión, Panamá pasó a ser parte negociadora en todos los asuntos referentes al canal.

Las negociaciones entre Estados Unidos y Panamá dieron origen al Tratado Hay-Bunau Varilla9 ${ }^{9}$, firmado el 18 de Noviembre de 1903, quince días después de desmembración del istmo. Este Tratado retomaban algunos puntos de las negociaciones mantenidas con Colombia, tales como la franja de soberanía norteamericana de 5 kilómetros a ambos lados de las excavaciones, la protección de la zona por parte de los Estados Unidos y la declaratoria de convertirla en área de circulación internacional ${ }^{10}$.

La separación de Panamá fue una afrenta para el Estado Colombiano y la constatación de la inutilidad de las guerras que habían caracterizado el panorama político durante todo el siglo XIX. Pero más que provocar un

\footnotetext{
${ }^{9}$ El Tratado completo se puede consultar en https://diegozpy.wordpress.com/2013/05/13/tratadohay-bunau-varilla-texto-original-y-analisis/ ingreso: 1 de febrero de 2015.

${ }^{10}$ Una perspectiva revisionista de la separación de Panamá puede verse en: Beluche, Olmedo. $L a$ separación de Panamá. Reflexiones en torno al centenario, Panamá, Imprenta Articsa, 2003.
} 
autoanálisis entre la élite colombiana acerca de su incapacidad para gobernar, desencadenó una posición de desconfianza frente a los Estados Unidos, y una reacción defensiva ante un hecho que se evalúo más como un un "robo"11 descarado, que como el efecto de los malos gobiernos que habían aquejado a Colombia desde su Independencia. Para los colombianos los panameños eran traidores, oportunistas e incapaces regir los destinos de la nueva república, por lo que consideraban que la segregación coincidía con el deseo de las elites istmeñas de convertir a la nueva república en un protectorado norteamericano.

A pesar de los desacuerdos el campo diplomático siguió activo, a partir de 1903 se desarrollaron negociaciones para que Colombia reconociera a la República de Panamá y normalizar las relaciones entre los dos países y entre estos y los Estados Unidos. Era más práctico obtener, al menos, una indemnización que resarciera parcialmente los efectos de la secesión, antes que enfrascarse en una lucha irracional con los Estados Unidos, quien a la postre defendía sus intereses protegiendo a Panamá. Muchos políticos colombianos se opusieron de manera vehemente al reconocimiento diplomático de la nueva República y levantaron sus voces ante las tentativas del Gobierno de negociar condiciones que favorecieran al país en el nuevo panorama político internacional.

Hubo varios intentos fallidos de restablecer los contactos diplomáticos y fortalecer la posición colombiana con respecto a Estados Unidos y Panamá. Entre las iniciativas se destaca el malogrado Tratado Cortés-Root de 1909 con el cual se buscaba regular las relaciones políticas Panamá y Estados Unidos, establecer claramente un área del Pacífico colombiano, en litigio, como soberana de Colombia, así como definir aspectos alusivos al uso del canal. Uno de los puntos sobresalientes de tales negociaciones era el reconocimiento a Panamá de su condición de República, asunto al que se opuso parte de la dirigencia política colombiana, aduciendo que esta acción constituía una traición a la patria y el reconocimiento de un acto ilícito de usurpación a la nación. En efecto, decía Francisco de Paula Mateus (1835-1919), uno de los más enconados opositores al pacto, que:

En el reconocimiento de la República de Panamá no se guardaron con Colombia las prácticas establecidas por el Derecho Internacional; era necesario proceder sin tardanza a asegurar para sus nuevos dueños la propiedad adquirida, sin que el autor del despojo le costara desembolso alguno, ni sacrificio de ninguna especie, ni otra cosa que el empleo de la fuerza, con violación de las eternas leyes de la justicia ${ }^{12}$.

${ }^{11}$ La idea de robo fue una constante en la historiografía colombiana de la época, véase a modo de ejemplo: Ortiz y Galvis, Los Estados Unidos y su robo de Panamá. Tratado de 1846. Antecedentes y consecuentes, Bogotá, s.n., 1920, que puede ser consultado en: http://admin.banrepcultural.org/sites/ default/files/85043/brblaa670718.pdf Ingreso: Febrero 3 de 2015.

${ }^{12}$ Biblioteca Luis Angel Arango (Blaa), Misceláneas 872. Informe que la minoría de la comisión encargada del estado de los Tratados celebrados por la República con los Estados Unidos de América y el Gobierno de Panamá presenta á la Asamblea Nacional Consitituyente legislativa., Bogotá, 1909. El documento completo puede consultarse en: http://www.banrepcultural.org/blaavirtual/historia/informeque-la-minoria-de-la-comision-encargada-del-estudio-de-los-tratados Ingreso: enero 23 de 2015 
Finalmente, el Tratado Urrutia-Thompson de 1914 redefinió las relaciones con Estados Unidos, reconoció la existencia republicana de Panamá y detalló los asuntos concernientes a la reparación moral y a las indemnizaciones que merecía Colombia por los sucesos de la desmembración del istmo, además aclaró litigios territoriales, definió las fronteras, estableció el monto de 25 millones de dólares como indemnización por los daños ocasionados por la secesión y normalizó, medianamente, las relaciones entre los estados implicados.

\section{Advertencia al lector}

El documento que transcribimos a continuación es la respuesta al debate suscitado en Colombia a raíz de las negociaciones del Tratado Cortés-Root. Enrique Cortés (1832-1912), diplomático colombiano responsable de la negociación y autor del texto que incluimos, fue un ferviente liberal que ocupó varios cargos públicos, entre ellos el de director General de Instrucción Pública (1868), durante el gobierno de los liberales radicales, fue encargado de los negocios entre Colombia y Estados Unidos en 1870. Se desempeñó como agente confidencial en Washington y negociador del tratado en cuestión, el que defendió de sus detractores por considerarlo beneficioso para Colombia. Aunque el tratado fue rechazado, algunos de sus puntos fueron incluidos en el Urrutia-Thompson de 1914

Nos parece que este documento recoge aspectos centrales sobre las negociaciones entre Colombia, Panamá y Estados Unidos, a la vez que su tono reposado demuestra la importancia de los conductos negociadores para el fortalecimiento interno de las repúblicas, así como para su prestigio exterior. Conservamos la ortografía de la época porque en el caso de Colombia el uso de determinadas letras como la conjunción $i$ en vez de $y$, el uso de las $j$ en vez de $g$, etc., denotaba la adscripción partidista, en este caso al liberalismo: Los conocedores de la historia del siglo XIX colombiano saben que el problema ortográfico no fue solamente un asunto de convención gramatical, fue sobre todo una postura que trazó las frontera ideológicas entre los partidos. No obstante, es preciso indicar que el en el uso ortográfico actual la región del litigio se escribe Juradó.

Advertimos al lector que parte de esta documentación puede ser consultada en línea en las colecciones virtuales que en la actualidad tienen la Biblioteca Luis Angel Arango y la Biblioteca Nacional de Colombia, instituciones que han dedicado grandes esfuerzos a digitalizar valiosos documentos para ponerlos al servicio de los investigadores de todo el mundo. 


\section{Biblioteca Luis Angel Arango (Bogotá) \\ Sala de Libros Raros y Manuscritos. Miscelánea 223.}

Cortés, Enrique. Los tratados de Colombia con los Estados Unidos y Panamá, Lóndres, C. Skipper, 1909.

\section{Los tratados con los Estados Unidos y Panamá}

Los tratados que como Representante de la República en Wáshington, he celebrado con los Estados Unidos y Panamá, finados el 9 de Enero último, han despertado considerable oposición en el país. A tal punto a llegado ella, que el Gobierno ha creido acertado y prudente, en deferencia á la opinión pública, el convocar al Congreso Nacional para que los tome en consideración. Sabia es esta medida, que permitirá el detenido estudio de ellos y hará que la decisión final sea tomada con premeditación y serenidad.

De las publicaciones que en contra de los Tratados se han dado á la prensa, y que han llegado á mi conocimiento, la mas autorizada y respetable ha sido el informe presentado sobre ellos por el Diputado á la Asamblea Nacional, honorable Señor Francisco de P. Mateus, en su informe como minoria de la comisión que aquel augusto cuerpo designó para su estudio, y que lleva la fecha del 8 de Marzo del corriente año. Aunque los argumentos allí aducidos se hallan superabundantemente contestados, tanto en el mensaje que al someter los Tratados á la Asamblea Nacional presentó su Señoría el Dr. Francisco J. Urrutia, Ministro de Relaciones Exteriores, como en el informe de la mayoría de la comisión, me ha parecido que estaba en mi poder el ofrecer algunas observaciones complementarias, que ayudasen á ilustrar el juicio del país entero y del Congreso Nacional. Esto explica mi intervención en el asunto, la cual hago con conocimiento del Gobierno.

El Señor Dr. Mateus considera inaceptables los Tratados por varias circunstancias.

Primera: Porque se reconoce la independencia de la República de Panamá, reconocimiento que no debemos hacer.

Segunda: Porque se somete á arbitramento la fijación de una parte de los límites entre Colombia y Panamá.

Tercera: Porque (dice) se concede dominio de soberanía a los Estados Unidos en nuestros puertos.

Cuarta: Porque se abra la puerta á reclamaciones inadmisibles por Colombia.

Finalmente, el Señor Dr. Mateus propone que se someta á la Corte Suprema de los Estados Unidos una demanda por los daños y perjuicios que representan el despojo de nuestra riqueza en Panamá. 
Analizaré someramente las cinco circunstancias anteriores, pero antes me permito llamar la atención al siguiente párrafo del informe:

"El Excmo. Sr. Presidente de la República, con honrado y patriótico interés, acreditó una Legación en Wáshington, y ésta inició las negociaciones de que vais á ocuparos, que desgraciadamente no corresponden á los deseos patrióticos del Sr. Presidente".

Ignoro si el Señor Dr. Mateus tiene fuentes de información más fehacientes que las que yo poseo, pero, tanto por la correspondencia oficial del ministerio con la legación, como por los documentos públicos ofrecidos a la Asamblea Nacional y al país por el Excmo. Señor Presidente de la República y por Su Señoría el Ministro de Relaciones Exteriores, se deduce clara, explicita y hasta encomiásticamente que el Ministro de Colombia en Wáshington signatario de los Tratados de 9 de Enero, se ciñó a las instrucciones recibidas y desempeñó su encargo á la plena satisfacción del Gobierno.

Primera objeción; Que no debemos reconocer la independencia de Panamá, tanto por las circunstancias que precedieron á ella y que la siguieron, cuanto porque ellos seria sancionar el crímen del 3 de Noviembre de 1903 y renunciar á la reparación moral y á la indemnización pecuniaria de millones de dólares que están obligados los Estados Unidos por habernos despojado de ingentes valores. Si el país opina como el Dr. Mateus, en esta primera objeción, evidentemente la negociación entera se derrumbará por la base.

No pretendo en manera alguna dotar de fuerza el punto de vista que tanto la República de Estados Unidos como Panamá, puedan alegar en justificación de sus procedimientos. Pero sí llamo la atención á que esos procedimientos se han ofrecido al mundo en puntos de vista distintos á aquellos que nosotros abrigamos; que Panamá para justificar su derecho á la independencia y que los Estados Unidos para justificar sus procedimientos, han saltado á la arena delante del mundo entero; que por razon del poderío americano o por cualquiera otra, la totalidad de este luctuosos drama, ha venido á cristalizarse en una sucesión de hechos cumplidos de tremendo carácter; que el mundo entero reconoce la independencia de Panamá y que los Estados Unidos se niegan rotundamente á traer al debate el forma alguna la cuestión de su culpabilidad en los acontecimientos ocurridos.

En frente de este, para nosotros sombrío cuadro de hechos cumplidos; en frente del perseverante empeño con que los Estados Unidos prosiguen la excavación del Canal que ha de ser la cúspide de su poderío; en frente del lisonjero porvenir que presiente Panamá; en frente de la expectativa de un desarrollo comercial extraordinario, una vez funcionando el Canal de Panamá, en frente de este cúmulo de incidentes á que contribuyen la riqueza y el poderío del mundo entero, en frente de él estamos nosotros, en el vórtice de la convulsión, pobres, en penosa situación económica y comercial y sin traer á la 
solución elemento alguno práctico, irritando nuestro estéril rencor, clamando venganza á una providencia sorda, y dejando crecer y crecer á nuestro alrededor este colosal Octopus que cada día llena mas de admiración al Universo.

El Gobierno del Excmo. Señor General Reyes, al instruir a la Legación de Colombia en Wáshington para no proseguir reclamación alguna por daños y perjuicios contra Estados Unidos y para reconocer la independencia de Panamá, si se podía hacer en términos honorables, me parece que ha demostrado clara visión del porvenir, que ha comprendido que nuestra política hoy debe ser la de mantener cordiales y amistosas relaciones con nuestros vecinos y cimentar y fortificar la buena voluntad respecto de los países latino-americanos que hoy surge visiblemente en todos los ámbitos de los Estados Unidos, y ponernos en la corriente de los acontecimientos que puedan aparecer. Se engañan quienes crean que los Estados Unidos son una nación exclusivamente de mercaderes. Hay mucho para nosotros que podríamos aprovechar de ellos, no solo en la industria y en el comercio, sino en la ciencia, en la ética, en la relijion, en la filosofía y en la literatura. Nuestro propósito debe ser cultivar sus relaciones como lo hacen Chile y Perú y la Arjentina y Méjico: todo á su gran provecho y progreso. En mi opinión la eventualidad de que los Estados Unidos vengan á indemnizarnos, no podría aparecer sino por algún que hiciera de tal suerte una reacción en el interior de ellos y que los obligase á aquella solución. Nuestra extrema debilidad, el inmenso poderío de nuestro vecino y la decidida actitud que ha tomado, imposibilitan el que nuestros esfuerzos culminen en un arreglo semejante al de las reclamaciones de los Estados Unidos contra la Gran Bretaña por las depredaciones de "Alabama" en la guerra civil. Las circunstancias del caso y el poderío de la nación reclamante, hacen imposible el establecer paridad en los dos casos.

El Dr. Mateus cita en apoyo de su opinión sobre que no debamos reconocer la independencia de Panamá, varios ejemplos, la oportunidad de los cuales no alcanzó a comprender. Uno de ellos que la independencia de Portugal y los Países Bajos no fue reconocida sino medio siglo después de su independencia; otro, que Inglaterra jamás reconoció los que surjieron de la Revolución Francesa; otro, que nuestra independencia no fue reconocida por España sino después de medio siglo. Estos ejemplos son contraproducentes. Los cambios en el mapa europeo á causa de la guerra continental del siglo 18, no vinieron a solucionarse sino por el triunfo de la Santa Alianza. En cuanto al lugar que tomaron las naciones agraviadas en reconocer la independencia de Portugal, Bélgica y las colonias hispano-americanas, ello seria á propósito si la dilación en el reconocimiento hubiere traído alguna ventaja material ó indemnización ó participación en las deudas primitivas en beneficio de las naciones desintegradas. El medio siglo que tardaron las naciones agraviadas en reconocer los hechos cumplidos, no tuvo mas efecto que irritar la mutua 
mala voluntad, que perder oportunidades valiosas de comercio, cambio de servicios y cordial amistad por muchos años, para terminar por donde se ha debido comenzar. Se dice que el necio acaba por donde comienza el cuerdo. $\mathrm{Y}$ esa es la verdad. Hoy se pretende reconocer los hechos cumplidos en un espíritu de buena política, de justicia, de benevolencia - por ello obtenemos no una pequeña parte de las obligaciones que gravan nuestro tesoro, solucionamos la cuestión de los límites, que puede andando el tiempo tomar un carácter agudo y peligroso, y allanamos el camino para entrar en una política realmente americana, de que tienen que ser ineludibles factores los Estados Unidos, y en el desarrollo de la cual nosotros estamos interesados mas que ninguna otra nación latina, por hallarnos en el vórtice mismo que habrá en lo porvenir de ser el eje de la política hispano-americana, es decir, á la inmediata vecindad del Canal de Panamá. Podremos es verdad dejar pasar media centuria ó una centuria completa, en lamentos y quejas estériles, durante la cual solo Dios sabe lo que habrá de ocurrir, y al fin terminaremos como España y los Países Bajos por cantar la palinodia, sin mas ventaja que lágrimas derramadas en vano y odiosidades estérilmente enconadas.

Si el triste pasado fuese bastante á darme alguna autoridad, yo me atrevería á recordar que va ya para varios años que el problema de nuestras relaciones con los Estados Unidos ha sido objeto de mis observaciones delante del público. El año de 1899 publiqué un folleto "El peligro americano" encaminado á detener la revolución que se veía venir. Mi objeto era desarrollar esta idea: "Nuestra proximidad á los Estados Unidos nos apareja peligros de desintegración, tanto por complicaciones internacionales, cuanto por el aliciente que tras de prolongado desorden interior, puede ofrecer á secciones del país la perspectiva de anexión á la Gran República, que les daría orden y progreso. Para desviar este peligro, el único preventivo es evitar las guerras civiles, las que ya se sabe, después de ochenta años de independencia, que no son suficientes para curar nuestras dolencias políticas".

El año de 1903, á propósito de la discusión sobre el Tratado Hay-Herrán. Hice varias publicaciones encaminadas á probar que, sin justificar los motivos, era un hecho inevitable que "al improbar esos Tratados íbamos á poner en inminente peligro la integridad nacional"

"El peligro americano" no evitó la pavorosa convulsión interior que asoló y arruinó el país tres años y medio de feroz contienda, que nos encontró desorganizados aún, exánimes y violentamente excitados en 1903, y que nos hizo rechazar el Tratado Hay Herrán perdiendo posición, influencia, riqueza y mirando desaparecer nuestra joya más preciada.

Todo lo hubiéramos podido evitar, pero no lo hicimos, Que el pasado nos sirva de lección para el porvenir. 
En mi bien sentada opinión, que he formado en los dos años y medio que he pasado en los Estados Unidos como representante de Colombia, que los Tratados de 9 de Enero se negociaron y firmaron en la época propicia; que corre hoy en todo el territorio de los Estados Unidos una onda de simpatía y de buena voluntad hacia las Repúblicas latinas. Que se comprende en los Estados Unidos los ánimos de susceptibilidad y desconfianza que animan y han animado el espíritu de la raza latina, y que existe vehemente deseo de todas las capas sociales de los Estados Unidos, de poner fin á esta situación y entrar en una vía de cordial y sincera amistad con los países latinos. En este movimiento aparecen como apóstoles y guías, el eminente estadista Elihu Root y el director de la oficina de las Repúblicas americanas, Johm Barret. Este movimiento es producto de múltiples elementos. Es comercial é industrial, porque cada dia se palpa mas la importancia creciente de los 60 millones de habitantes que forman la raza latina en América; es de social simpatía, porque cada dia se reconocen, se estiman y aprecian mejor los bellos y nobles rasgos de inteligencia y de carácter que distinguen á nuestra raza; es de ética y justicia, porque se reconoce que el pasado por parte del pueblo americano, está abierto á cesuras; y es de política internacional, porque es posible que el porvenir traiga como factor en la historia de América la influencia de naciones asiáticas.

Pero de aquí á que los Estados Unidos consientan, después de la repetida exposición de su política respecto á nosotros, en comprar á costa de una confesión de culpabilidad, el adelanto de esta política hoy en pleno viento favorable, la distancia es inmensa.

Cuidando con alhagarnos por esperanzas fantásticas como nos sucedió en el Tratado Hay Herrán. Preciso es no olvidar que el que dá pronto dá dos veces. Preciso es también no olvidar que el momentum de cordialidad americana está secundado por la mayor parte de las naciones latinas, y que nuestra displicencia no sería decisivo factor en la política de nuestras hermanas.

Segunda objeción: El arbitramento sobre la línea final de Altos de Aspave al Pacífico.

Dice el artículo IX del Tratado con Panamá:

"Es conveniente entre las Altas Partes Contratantes y así se declara, que la línea divisora entre la República de Panamá y la República de Colombia será como sigue:

Partiendo de Cabo Tiburón en el Atlántico á las Cabeceras del Río de la Miel y siguiendo la cordillera por el Cerro de Candi á la sierra de Chugargún y la de Mali á bajar por los cerros de Nique á los altos de Aspave y de allí en dirección al Pacífico hasta aquel punto y por aquella línea que se determinen por el Tribunal de Arbitramento que más adelante se establece, debiendo conformarse a determinación de dicha línea á la decisión del Tribunal de Arbitramento de que más adelante se trata. 
En cuanto al territorio que se somete á arbitramento (la región de Jurado), es entendido que los límites y la adjudicación de ella á cualquiera de las Repúblicas de Panamá ó Colombia, se fijarán por la determinación de la línea antedicha que hará el citado Tribunal de Arbitramento, el cual Tribunal resolverá, tanto sobre el título de propiedad y sus límites precisos, como sobre el derecho de soberanía sobre ella que se discute entre las dos Partes Contratantes, y la determinación del Tribunal se considerará definitivamente establecida por arbitramento, conforme a las siguientes formalidades:

Se creará un Tribunal de Arbitramento que investigue y determina todas las cuestiones de hecho y de derecho respecto á los derechos de las Altas Partes Contratantes á ó en todo el territorio de la mencionada región de Jurado.

El Tribunal se compondrá de tres miembros; la República de Panamá nombrará un miembro, la República de Colombia nombrará un miembro, los cuales serán nombrados dentro de los tres meses después del Canje de las ratificaciones de este Tratado, y los dos miembros del Tribunal así nombrado, conjuntamente, nombrarán al tercero, ó en caso de que no logren ponerse de acuerdo dentro de los tres meses después del nombramiento del último de ellos, y á solicitud del Presidente de cualquiera de las Altas Partes Contratantes, el tercer miembro del Tribunal será nombrado por el Presidente de la República de Cuba.

El Tribunal celebrará sus sesiones", etc., etc.

El Señor Dr. Mateus observa lo siguiente á propósito de este artículo, después de citar la línea de límites establecida por la ley de 9 de Junio de 1855:

"Por el artículo $5^{\circ}$ de la Constitución de Rionegro se dispuso que los límites de los Estados Unidos (de Colombia), creados por leyes anteriores ó actos constitucionales, no pudieran variarse sin el consentimiento de los mismos Estados, y por el artículo 42 de la Constitución de 1886 los Departamentos reemplazaron á los Estados, conservando los límites que estos tenían antes. No hay, en consecuencia, cuestión alguna de límites con Panamá, y sin embargo en el artículo IX del Tratado se establecen un Tribunal de Arbitros para fijar la línea de demarcación del territorio que separe el que corresponde a cada una de las partes, comprendidas por el fallo arbitral, debiendo respecto de la región de Jurado resolver á cuál de ellas pertenece en propiedad y soberanía. ${ }^{13^{*}}$

“ No estando determinados los límites de esta región, los árbitros pueden fijarlos hasta la Bahía de Cupica, en el Pacífico, extremo sur del Canal del Atrato, y anular así esta vía interoceánica, que puede ser en lo por venir fuente de riqueza para Colombia.

Para constituir el Tribunal la República nombrará un árbitro, Panamá otro, y si éstos no se pusieren de acuerdo en un tercero- y es claro que este acuerdo nunca tendrá lugar- el tercer miembro del Tribunal será nombrado por

\footnotetext{
13 * Las líneas en letra cursiva son una maliciosa é inexacta descripción del arbitramento convenido; basta leer el artículo IX para convencerse de esto (cita del texto original)
} 
el Presidente de la República de Cuba, o lo que es lo mismo, por el Gobierno de los Estados Unidos, de modo que el Tribunal es innecesario, porque quedando en él Colombia sin defensa, de hecho se entrega la región de Jurado a Panamá."

Tres aserciones á cual más insostenibles contienen los párrafos citados;

1. Que no hay cuestión de límites con Panamá.

2. Que la región de Jurado puede fijarse hasta la Bahía de Cupica extremo sur del Canal del Atrato.

3. Que si Cuba nombrase el tercer árbitro la decisión sería la que dictasen los Estados Unidos, es decir en favor de las pretensiones de Panamá.

Primero: Si estuviese Colombia tratando con Colombia, es claro que no habría cuestión de límites, pero como se negocia con un tercero, es evidente que se necesita un acuerdo; al no llegarse á este acuerdo, aparece la diferencia sin remedio, Tan es evidente que hay cuestión de límites, que es ella la que ha causado mas graves y tormentosos debates en las negociaciones. La correspondencia y las deliberaciones llevadas á cabo por parte de Panamá para dilucidar la cuestión de los límites, llenaría varios volúmenes. El asunto se trató en los años de 1906 y 1907, estando presente Mr. Buchanan, representante del Gobierno americano. Panamá por su parte, por medio de su hábil apoderado Mr. Cronwell, sostuvo á capa y espada que los límites á que tenía derecho su mandante era la línea fijada por un decreto del General Mosquera del año de 1847, sobre la demarcación del Territorio de Darién, ó sea -por el Este del Río Atrato desde su desembocadura hasta su confluencia con el Napipi; por el Sur, este Rio en toda su extención una línea recta desde su origen hasta la Bahía de "Cupica".

Se vé, pues, que la diferencia no podia ser más considerable. Mi objetivo en ese largo espacio de tiempo fue el de lograr que el Gobierno americano reconociese que la línea de los límites, ó sea lo mismo, la limitación de su protectorado en favor de Panamá, era la demarcada por la ley de 9 de Junio de 1855 y que Colombia estaba dispuesta á aceptar. No perdí las esperanzas de lograrlo y en tal camino rechacé las varias propuestas de Panamá para someter la cuestión general de límites á una decisión arbitral. En mi opinión si aquel reconocimiento se obtenía, nuestra posición se haría notablemente mas fuerte y aún se tuvo en mira dejar en silencio la cuestión de límites, que estaría prácticamente definida por la declaración americana. Mi idea era que si los Estados Unidos reconocían nuestros límites, quedaríamos en libertad de ocupar á Jurado, sin temor de oposición por parte de ellos y esperando que al dar este paso la cuestión provocaría una crisis, que haría irresistible el acuerdo en alguna especie de entendimiento sobre los límites.

Por fin en el mes de Agosto de 1907, después de una larga conferencia con Mr. Root en Nueva York, obtuve su promesa de que escribiría una carta en este 
sentido. Así sucedió en efecto, habiendo recibido dicha carta el 26 de Agosto de 1907 y que dice así:

"Tengo el honor de acusar recibo de su carta fechada el 18 del corriente, en la cual Ud. describe lo substancial de lo ocurrido en la entrevista que tuvimos en el Hotel Gotham en Nueva York el 16 del corriente mes, sobre la descripción de la línea de límites con Panamá, según aparece de la ley de Nueva Granda de 9 de Junio de 1855, y en cuya carta Ud. solicita una exposición de parte de los Estados Unidos respecto á su punto de vista en lo relativo á la línea de límites entre Colombia y Panamá, todo de acuerdo con la manifestación verbal que yo le hice en nuestra entrevista.

La relación que Ud. hace de lo ocurrido en la entrevista, se halla enteramente de acuerdo con mis recuerdos y vengo por la presente á confirmar lo que dije á Ud. verbalmente, á saber que la opinión de los Estados Unidos es que la línea de límites entre Colombia y Panamá es la que aparece descrita en la ley de Nueva Granada arriba mencionada de fecha de 9 de Junio de 1855.

Esta es la misma opinión que originalmente se formó Mr. Buchanan y con la cual estoy de acuerdo, después de haber examinado cuidadosamente los varios documentos que se han tenido en cuenta en las recientes negociaciones, los cuales no me parece que justifiquen cambio alguna de aquella opinión, lo cual puede Ud. considerar como la madura y definitiva posición del Gobierno de los Estados Unidos.

Me repito de Ud. mi estimado Sr. Cortés (Firmado) Elihu Root.”

Imposible desconocer la importancia de esta carta que define la posición de los Estados Unidos en punto á nuestros límites y que desde luego les ata las manos para intervenir en modo alguno en la cuestión de límites. Pero es evidente que por importante que sea, ella no lo puede ser tanto como un Tratado entre las dos partes interesadas que defina perpetuamente la diferencia. La declaración americana puede en algún evento abrogarse por la rama ejecutiva del Gobierno que la dictó, ó puede cambiarse por superior decisión del Senado. Estas dos posibilidades desaparecen al definir la línea de límites en un Tratado directo con Panamá. Por esta razon yo no abandoné la idea de llegar á este resultado. Pareciome que la ocasión sería la de ocupar a Jurado, lo que podríamos hacer sin temor de intervención americana. Tomado este acto de presencia, la cuestión tendría que llevarse á una crisis, tocando con este cauterio lo vivo de la llaga; este vivo de la llaga es Jurado; punto sentimental y obstinado de interés por parte de Panamá y respecto del cual su representante ha sostenido intensamente que "los derechos de Panamá á este respecto no se hallan incluidos en la disputa general sobre límites entre Colombia y Panamá, considerando eta que independientemente de aquella cuestión de límites, no hay argumento alguno razonable que milite contra lo irrecusable de su derecho 
a la posesión de Jurado (nota del Señor Arango al Departamento de Estado de 13 de Abril de 1908).

En efecto en Marzo de 1908 el Gobierno colombiano ordenó la ocupación de Jurado.

La situación creada por este acto del Gobierno colombiano en lo relativo a la actitud de Panamá se halla bien descrita en los siguientes párrafos tomados de la memoria presentada por el Secretario de Relaciones Exteriores de Panamá a la Asamblea Nacional en 1908.

" Relaciones Diplomáticas

Con todas las naciones que han reconocido a la República de Panamá há seguido ésta cultivando las más cordiales relaciones de amistad como lo veréis en el curso de este Informe. Con la República de Colombia se han adelantado importantes y laboriosas negociaciones para un tratado de amistad y para el arreglo de las cuestiones surgidas de nuestra separación. Estas negociaciones llegaron en Agosto del año próximo pasado hasta la firma de un protocolo que aún permanece bajo reserva diplomática; pero desgraciadamente al ser discutido el tratado respectivo, surgió el incidente relacionado con los límites de las dos Repúblicas y la subsiguiente ocupación de Jurado por fuerzas colombianas, incidente que ocasión la paralización de la gestión principal.

En vista de la gravedad de estos sucesos, el Gobierno creyó conveniente calmar la ansiedad pública y para situar la cuestión en el punto elevado y sereno que las circunstancias indicaban, dar cuenta de ellos á la Nación, lo que hizo por medio de sus representantes más autorizados residentes en esta capital, quienes fueron convocados para una reunión en el Palacio Presidencial.

En el acta de esta reunión, que tuvo lugar el día 3 de Abril de presente año, hallaréis los detalles concernientes á este asunto y claramente expuesta la actitud de la Cancillería.

Como consecuencia de lo acordado en esta reunión, el 4 de Abril citado, este despacho impartió órdenes a nuestra Legación en Wáshington para suspender toda comunicación oficial con el Ministro de Colombia y para demandar formalmente al Gobierno de los Estados Unidos el cumplimiento de la garantía del mantenimiento de nuestra independencia conforme á la obligación que contrajeron para con la República de Panamá al tenor del artículo primero de Tratado Hay-Buneau-Varilla. En sustancia los fundamentos de esta demanda los hacia depender mi antecesor de la siguiente argumentación:

Si no fuera porque la marcada deferencia que el Secretario Root ha demostrado hacia Colombia, en carta semi-oficial al Ministro Cortés, en la cual se pronuncia en contra nuestra, sin habernos oído, esta Cancillería no tendría el menor recelo de la actitud que tomarán los Estados Unidos ante la demanda nuestra; pero como quiera que esta desfavorable circunstancia es evidente, debo encarecer a Vuecencia 
revista su demanda de toda la fuerza de argumentación y seriedad que demanda el caso.

Hecha la gestión correspondiente por nuestro Ministro en Wáshington, quien fue autorizado para proponer el arbitraje como medio de resolver la dificultad, el Departamento de Estado contestó que el Gobierno de los Estados Unidos no consideraba llegado el caso de hacer efectiva la garantía de la Independencia de Panamá, consignada en el artículo $1^{\circ}$ del 18 de Noviembre de 1903, porque no puede considerarse al tenor del citado artículo: ${ }^{14}$

Que los Estados Unidos tengan la obligación de apoyar la opinión sostenida por el Gobierno de Panamá en cualesquiera controversias que ella pueda tener con otra naciones, con indiferencia de la opinión de los Estados Unidos sobre el derecho o sinrazón de tales controversias y sin tener ningún control sobre la acción que sería conveniente ó deseable para el propósito de efectuar alguna transacción ó convenio diplomático de tales cuestiones. Es posible que muchas consecuencias ofensivas y perjudiciales puedan resultar en el camino que adopte Panamá en sus negocios internacionales, pero hasta tanto estas consecuencias no hagan temer la sujeción a otro poder y por tanto amenacen su independencia, la obligación de los Estados Unidos, de acuerdo con la citada garantía, no parecerá requerir acción.

Aún sin ser constreñido por la obligación de esa garantía es, sin embargo, el mayor deseo de los Estados Unidos fomentar por su influencia y su acción en todas las maneras posibles la prosperidad y el engrandecimiento de la República de Panamá y mientras en las cuestiones de límites que existan entre Panamá y Colombia, por una parte, y entre Panamá y Costa Rica, por otra, no surjan francamente puntos que envuelvan algún daño para la independencia de Panamá, el Gobierno de Estados Unidos prestará con gusto sus buenos oficios si ellos pueden ser utilizados, respecto del arreglo de esas controversias. Con especial referencia al pequeño territorio incluido dentro de la denominación de Jurado, este Gobierno ha estado inclinado á creer que están escritos en la ley de la Nueva Granada de 9 de Junio de 1885. En una Nota al Señor Cortés, escrita por mí el 26 de Agosto último (copia de la cual fue transmitida a la Legación de Ud. con mi carta personal de 17 de Febrero último) expuse que esta fue la creencia expuesta primeramente por el Señor Buchanan y sustentada por mí mismo y que un cuidadoso examen de los varios documentos que habían sido aducidos durante las recientes negociaciones, no habían parecido suministrar ningún fundamente justo para un cambio de tal creencia que él (el Señor Cortés) puede considera como la juiciosa y definitiva opinión de los Estados Unidos.

${ }^{14}$ Lo que sigue son párrafos de la nota americana al representante de Panamá (cita del texto original) 
Esto así, el derecho sobre Jurado parece depender de la posición de un pueblo y su jurisdicción con referencia á la línea de 1855 .

En vista de la carta del Señor Arango, de 13 de Abril de 1908, de que los derechos de Panamá sobre la aldea de Jurado y sus límites jurisdiccionales descansan sobre hechos y consideraciones que no están comprendidos en la disputa entre Colombia y Panamá sobre la línea de los límites en general, el Gobierno de los Estados Unidos ha estado justificado ya al hacer el uso de sus buenos oficios con el Gobierno de Colombia en el sentido de sugerir un arbitramento. Antes los Estados Unidos no tuvieron autoridad alguna para comprometer á Panamá en la cuestión y naturalmente ni obtuvo ni estaba autorizado para recibir una respuesta terminante y que creara una obligación de parte del Gobierno de Colombia; sin embargo, este Gobierno está satisfecho, por las comunicaciones verbales que ha cruzado sobre el asunto, de que el Gobierno de Colombia estaría dispuesto á entrar en un arbitraje relativo al título sobre Jurado, siempre que la línea general de límites entre los dos países, excepto en lo referente á Jurado, sea aceptada tal como está descrita en la ley de 1855. Si el Gobierno de Panamá desea eso, el Gobierno de los Estados Unidos procederá á adelantar el ejercicio de sus buenos oficios en esta forma; el Gobierno de los Estados Unidos será muy feliz de hacerlo así.

Esa declaración lleva la fecha de 14 de Mayo, y al mismo tiempo estaba en viaje de regreso para los Estados Unidos el Secretario de Guerra de dicha Nación, Honorable William Taft, después de las conferencias que celebró en esta ciudad dicho alto funcionario con mi antecesor y nuestro Ministro en Wáshington, Señor Arango, con el Concurso del Consejero Legal de la Legación, Doctor William Nelson Cromwell.

En estas conferencias fue tratado el asunto de Jurado, no solo verbalmente, sino con la presentación de una exposición documentada y debidamente traducida al inglés, en que se dilucidaba la cuestión de nuestros derechos sobre la línea general de límites con Colombia que reclama Panamá y nuestros derechos jurisdiccionales sobre Jurado, en particular, de una manera extensa y al parecer concluyente.

Esto no obstante no me es posible anunciaros ningun cambio en la situación, debido á que, según informó nuestro Ministro en Estados Unidos en nota de fecha de 23 de Junio pasado, ocurrió en la oficina del Honorable Secretario Root con el objeto de acordar algo acerca de varios asuntos, entre ellos principalmente el de Jurado, y la contestación que obtuvo fue "que al regreso del Secretario Taft y en vista de como había este juzgado las cosas aquí, habían creido conveniente no hacer nada sino hasta después de las elecciones y por lo tanto no había objeto en gestionar por ahora. 
Hay que esperar, pues, á que llegue la época fijada por el Secretario de Estado, para reanudar nuestras gestiones, para lo cual ya ha impartido mi antecesor á la Legación en Washington muy prudentes y acertadas instrucciones"

\section{(Hasta aqui los párrafos de la memoria)}

Por la lectura de lo anterior se comprenderá que la actitud de los Estados Unidos respecto de nosotros, en vez de ser hostil y agresiva, ha sido amistosa y justa; que su actitud en cuanto á no imponerse en la decisión de los límites, es perfectamente clara y definida. Se verá además por ellos cómo lo relativo a la posesión de la "Rejión de Jurado" está clara y concretamente expresada, lo cual tendrá que pesar en la demarcación del territorio en disputa, llegado el caso de un arbitramento.

Incluso aquí un plano de la parte del territorio del Istmo que comprende la diferencia de límites, apareciendo allí bien clara la línea de límites de la ley de 9 de Junio de 1885 que reconocieron los Estados Unidos; la extensión de la línea que reconoce Panamá en el Tratado y que comprende las nueve decimas partes de la línea total, libertando de toda posterior diferencia la inmensa hoya del Atrato, desde su desembocadura hasta una distancia de 20 millas, mas ó menos, de Pacífico, ó sea la línea desde los Altos de Aspave; aparece también la línea materia del arbitramento y la línea total de límites que reclamaba Panamá originalmente.

Según la memoria del Señor Alfaro las negociaciones quedaron suspendidas hasta después de las elecciones de Presidente de Panamá y en el punto en que la Legación de Colombia se hallaba dispuesta á someter á arbitramento lo relativo a la posesión de Jurado por si solo con tal de que Panamá aceptase la línea de la ley de 1885, desde el cabo Tiburón en el Atlántico hasta los altos de Aspave, distancia de 15 á 20 millas del Pacífico. Acepté esta transacción porque me pareció que á trueque de que se reconociese la inmensa línea de Tiburón á Aspave, valía la pena correr con el riesgo de un arbitramento sobre la dirección de la incierta línea de Aspave al Pacífico. Asegurar contra toda eventualidad la inmensa y rica hoya del Atrato, valía la pena en mi opinión de correr el riesgo de perder unas cuantas millas de tierra desierta y de poca importancia hacia el Pacífico. Visto el empeño de Panamá de no ceder a Jurado y visto el peligro de no firmar el Tratado, acepté lo que consideré ventajosa transacción.

Teme el Dr. Mateus que lo que se llama en el Tratado la "Rejión de Jurado" puede llevarse hasta la Bahía de Cupica, extremo sur del Canal del Atrato,

Puedo calmar los temores del honorable diputado. Por los términos del artículo IX es entendido que la línea que se fije de altos de Aspave será en dirección al Pacífico, y se refiere á la región de Jurado. Esta expresión no puede en buena lójica aplicarse á una extensión indefinida de territorio que se halla á 
gran distancia del pequeño caserio de Jurado, que parece tener una centena de habitantes. Rejión es término limitado, de significado gramatical y no político o geográfico. Realmente la disputa, en vista de estos antecedentes, se refiere a Jurado, pero se puso Rejión de Jurado, para incluir sus límites jurisdiccionales, caso de que ocurriesen argumentos que la justificasen en espíritu de justicia. Rejión de Jurado, no puede extenderse á mucha distancia de este pequeño caserio que formaba el eje de la disputa. En suma, el Señor Arosemena, representante de Panamá, manifestó al firmarse el Tratado que en la expresión, Rejión de Jurado, él entendía una extensión limitada al lado de Colombia por el curso de río del mismo nombre, y este testimonio se aducirá llegado el caso si hubiere necesidad.

Mas no debemos perder de vista que no se trata de que vamos á perder territorio á todo trance, pues nuestra actitud en el arbitramento es nuestro derecho á la línea que no han reconocido en los Estados Unidos, pero en la cual hay que fijar siempre la dirección de la línea de Aspave al Pacífico, entre Cocalito y la Ardita. Cualquiera que sea la extensión que encarne la disputa, el temor de que pueda intervenir con la salida al Pacífico de un canal interoceánico, me parece perfectamente imajinario. La excavación de un canal interoceánico por la hoya del Atrato es perfectamente imposible en considerable espacio de tiempo. Primero, porque los Estados Unidos no lo permitirían. El canal que se está excavando á tan tremendo costo y trabajo, es una empresa de carácter exclusivamente extratéjico, encaminado á enlazar sus posesiones de ambos mares y su comunicación con el Oriente y el Occidente de Universo. Permitir la excavación de un canal contiguo, que no estuviera bajo su control, sería nulificar por entero el carácter extratéjico del Canal de Panamá. Desde luego la declaración del Presidente Hayes no deja duda al respecto. Al tío Samuel se le atribuyen toda especie de malicia y de marrullas. Tan solo el deseo de hostilizar al Gobierno del General Reyes puede hacer parecer el pueblo americano delante del nuestro, dotado de tan sublime candidez, Segundo, porque el costo de un canal por el Atrato seria enormemente superior (como los estudios lo han demostrado) al de Nicaragua, que pudiera ponérsele en competencia. Tercero, porque no habrá nación europea ni grupo de naciones que se embarcase en tan peligrosa empresa. Esta actitud se hizo patente antes del fracaso de la Compañía nueva del Canal de Panamá, cuando el ingeniero Buneau Varilla recorrió todas las Cortes Europeas buscando ayuda y cooperación para la bamboleante empresa, obteniendo unánimemente la misma respuesta: "imposible mezclarnos en un asunto que pudiera acarrear complicaciones con los Estados Unidos". Cuarto, porque seria imposible, aún caso de que los Estados Unidos lo permitieran, el que se obtuviera el capital necesario en Europa para una empresa de carácter comercial, visto que la competencia que le haría el Canal de Panamá sería irresistible por cuanto á que esta, que no tiene carácter comercial, podría 
ofrecer al comercio condiciones y términos inaccesibles para su rival y que lo arruinarían.

Se han circulado en Colombia rumores que han merecido crédito sobre que bajo los auspicios de la Sociedad Geográfica de Londres se están haciendo estudios para un canal por el Atrato que se organiza en Lóndres una sociedad o sindicato para tal objeto. Todo esto es pura invención y fantasía. Para averiguar la verdad le escribí al bien conocido explorador é industrial, Coronel George Earl Church, Miembro del Consejo Directivo de la Sociedad Geográfica de Lóndres, quien me contestó en los términos siguientes:

"216 Cromwell Road

Londres, Marzo 26 de 1909

Mi querido Señor Cortés:

En respuesta á su atenta carta de 14 del corriente relativa á lo que han publicado varios diarios que el Presidente de la Real Sociedad Geográfica favorece un proyecto de canal interoceánico por el Atrato, que rivalice al de Panamá, le diré que la idea es tan absurda que realmente no vale la pena contradecirla. Ni el anterior ni el actual Presidente de la Sociedad han pensado jamas en semejante cosa, ni siquiera se han ocupado del incidente del proyecto.

Puede Ud. hacer el uso que crea conveniente de esta carta.

De Ud. Affmo. amigo

(Firmado) George Earl Church

Miembro del Consejo Directivo de la R. S. G.”

Desbaratada pues la pretendida importancia de la hoya del Atrato como via para un canal, le resta solo la muy importante que tiene por su topografía y riqueza de suelo. En este camino, el Tratado de 9 de Enero con Panamá salva y garantiza contra toda eventualidad la hoya mencionada por el reconocimiento de límites que comprende las nueve decimas partes de su extensión en línea paralela al curso del Atrato. Si hubiera peligro alguno, el Tratado lo conjura, mientras que al no firmarse él, quedará dicha línea en absoluta incertidumbre con Panamá y en cierto grado de ella con los Estados Unidos, por lo que arriba he mencionado.

Asegura el Dr. Mateus que la decisión arbitral será la que dicten los Estados Unidos, por cuanto á que el árbitro nombrado por Cuba, si hubiera lugar a ello, lo que así pasará en opinión del Dr. Mateus, hará lo que disponga los Estados Unidos.

Lo anterior implica que los Estados Unidos tienen interés y ejercerán su influencia sin contemplaciones para que la línea de límites al lado del Pacífico sea lo más favorable posible para Panamá. Implica además que Cuba será maniquí sin conciencia ni raciocinio, al mandato y disposición de los Estados Unidos.

Desde luego el Dr. Mateus no alega razón alguna para sus afirmaciones. Pero como obras son amores y no buenas razones, veamos la verdad de los hechos. Si los Estados Unidos tienen interés y deseo de perjudicarnos ó de 
favorecer a Panamá en la pequeña región de Jurado, es evidente que también los habrán tenido de igual naturaleza y con mayor razón, en lo relativo á todo el resto de la línea que cubre la extensa e importante región del Río Atrato.

Si tal es la situación, cómo y porqué se explica el que los Estados Unidos, en vez de favorecer a Panamá en sus pretensiones sobre límites, han reconocido toda la línea de nuestra ley de 9 de Junio de 1855, dejándonos en libertad de ocupar á Juradó rehusando su protección á Panamá y declarando que no tienen porque mezclarse en disputas internacionales de Panamá, a menos que se amenace su independencia?.

Qué explicación humana y racional tienen este procedimiento, como no se la que yo les doy, á saber que los Estados Unidos no tienen interés ni deseo ni pretenden mezclarse en la demarcación de la línea de Juradó sobre la cual ya han trazado su manifestación que es favorable á las ideas de Colombia. Me parece que todo esto es tan claro como la luz del Sol. Pero hay criterios de antemano prevenidos, para quienes la suspicacia á todo tranque es equivalente á penetración y agudeza de ingenio.

Esta cuestión del arbitramento la consideré de poca importancia; la juzgué como un procedimiento sencillo, de buena fe, conciliador y deferente y concedí en mi mente tanto a los Estados Unidos como a Panamá el mismo espíritu de justicia, deferencia y conciliación que animó y ha animado al Gobierno colombiano.

Yo no he visto sombras de mala fé ó de "arrière pensé" y me complazco en creer que todos hemos procedido de buena fe y de manera honorable.

En cuanto á la intervención del Gobierno de Cuba como designador del tercer árbitro y á la probable decisión del tribunal, debo decir que la selección de dicho Gobierno, que acepté al rechazarse varios de una y de otra parte, me pareció honorable y discreta. Si algo pudiese haber en el ánimo de aquella simpática e interesante nación respecto de nosotros, sería lazos de amistad y gratitud.

Al aceptar á Cuba recordé que ella mereció las primeras miradas del Libertador Bolívar al terminar su tarea libertador en el continente y que tuvo el proyecto de invadirla y libertarla, lo que hubiera hecho sino hubiera encontrado oposición internacional; recordé que sangre de colombianos ha regado los campos de cuba en la campaña de insurrección, la mayor parte caucanos, entre ellos el gallardo N. Conto y Aurelio Rosas. Recordé el entusiasmo con que fueron recibidos en Colombia y los no pequeños ausilios que recibieron en dinero los dos Generales Quesada cuando buscaron ayuda en nuestro suelo.

A un gobierno tan honorable como el del General Gómez no se le puede acusar sin intemperancia de juicio de una sumisión ciega en cuestiones de honra y dignidad internacionales, caso de que los Estados Unidos exijiesen, lo que no creo, una ciega capitulación con la justicia. 
Tercera objeción: Que el artículo IV del Tratado con los Estados Unidos conceda á estos el uso de soberanía sobre nuestros puertos á tal punto que los Estados Unidos pueden construir fortificaciones en ellos y establecer estaciones carboníferas.

De dónde se pueda deducir tal resultado, es simplemente sorprendente.

Dice así el Artículo IV:

"La República de Colombia concede á los Estados Unidos el uso de todos los puertos de la República que estén abiertos al comercio, como lugares de refugio para cualesquiera buques que estén empleados en la empresa del Canal, y para todos los buques en desgracia que pasen o se dirijan al Canal y que busquen abrigo o anclaje en dichos puertos, quedando este permiso sujeto en tiempo de guerra á las leyes de neutralidad que sean aplicables al caso. Tales buques estarán exentos de todo pago por derecho de anclaje o tonelaje a la República de Colombia"

Se ve claramente que lo que se concede es aquello mismo que la leyes internacionales reconocen, á saber el uso como lugar de refujio, sujeto a este permiso á las leyes de neutralidad en tiempo de guerra. De dónde, el uso como refujio de un puerto, es decir en caso de desgracia ó peligro pueda llevar al establecimiento de fortificaciones ó carboneras, es superior a toda humana interpretación. Y si es así también se podría alegar que igual derecho se reconoce á todas las naciones cuyos buques se dirijan al Canal á quienes también se les concede igual derecho. La verdad es que este artículo se insertó como explicación o fundamento de la esención de derechos de anclaje y tonelaje.

Por lo demás es conveniente informar al público que sobre el alcance de este artículo se han cambiado notas, tanto entre el Departamento de Estado y la Legación de Colombia en Wáshington como entre nuestro Ministro de Relaciones Exteriores y la Legación americana en Bogotá, que ponen en punto fuera de toda posible duda y salvan por entero los derechos de soberanía nacional.

Cuarta objeción: El artículo IV del Tratado con Panamá que reconoce el derecho mutuo de los individuos para presentar reclamaciones contra el Gobierno de otra nación. Este derecho se podía negar, pero se puso la limitación á las demandas que pudieran presentarse y que no estuvieren apoyadas por las leyes vigentes el 3 de Noviembre de 1903. Se comprende desde luego que abrir la puerta de un Tribunal no implica el reconocimiento de la demanda, la cual tendrá que sujetarse á los trámites de legalidad vijentes en la nación demandad y á los derechos de justicia internacionales.

Lo que se ha reconocido es un principio, no una reclamación cualquiera. Con ó sin Tratado, ninguna nación puede cerrar de antemano las puertas de sus tribunales de justicia. 
En cuanto á la determinación que aconseja el Sr. Mateus de someter el punto relativo á nuestro derecho de indemnización, á la decisión de la Corte Suprema de los Estados Unidos, me parece singularmente peregrina y nueva. Someter al adversario la resolución de un punto litijioso con él, causaría sorpresa en el mundo diplomático. ¿Qué dirían Chile y Perú si se les propusiera una solución idéntica en su caso? Desde luego es imposible rendir un mas alto homenaje á su adversario que someter á su criterio la solución del pleito.

Lo que me admira en este caso, es que sea la misma pluma que tan alta idea manifiesta sobre la honorabilidad de los Estados Unidos, la que haya trazado aquellas líneas de tan extrema suspicacia referentes á la intervención de los Estados Unidos en la decisión del arbitramento sobre Juradó y otros puntos en que abunda la mala voluntad, los dos puestos conceptos no se compajinan muy bien.

En su afán de encontrar motivo de censura en los Tratados, el Dr. Mateus no aprueba que se reciban en dinero los dos millones y medio que nos pagará Panamá por su participación en las deudas: preferiría que Panamá amortizase bonos colombianos ó se entendiese directamente con los acreedores. Hasta donde le convenga á una nación prestadora de dinero en el mercado, el que su deudor amortice sus créditos directamente, es lo que cualquier financista puede decidir fácilmente, Y cómo se haría todo esto sin reconocer á Panamá, sería otra dificultad.

Sensible es que no tengamos buques de guerra hoy en día. Pero ellos vendrán con la necesidad de los tiempos. El Canal de Panamá prestará á Colombia un servicio idéntico al que presta á los Estados Unidos, el carácter de un canal estratéjico y poderoso factor en el mantenimiento de la paz pública interior de nuestra integridad nacional, no menos que en el caso de una guerra extrajera. Asegurar, pues, como se asegura por el Tratado con los Estados Unidos, el paso fácil y no interrumpido por él, es asunto de vital importancia para nuestro porvenir. Entonces aparecerá la necesidad de tener marina de guerra, para lo cual no faltarán los recursos llegado el caso, como no los faltan para cimentar la pública administración a medida que las necesidad de la civilización exijen mayores desembolsos. Los Tratados de 9 de Enero sin duda que adolecen de efectos; pero en mi opinión fue lo mejor que se pudo hacer. Entre aceptarlos y dejar la cosa en situación incierta y equívoca, es preferible lo primero, que la solución a cuestiones de importancia capital.

En cuanto a mí, he trabajo sin descanso hasta donde mis capacidades lo permiten y entrego con tranquilidad mi labor al fallo de la historia.

\section{Enrique Cortés}

Londres, Mayo de 1909 
